\title{
SÍNTESIS PALEONTOLÓGICA DEL CÁMBRICO Y ORDOVÍCICO DEL SISTEMA IBÉRICO (CADENAS IBÉRICAS Y CADENAS HESPÉRICAS)
}

\author{
Eladio LIÑÁN ${ }^{1}$, Enrique VILLAS ${ }^{1}$, Jose Antonio GÁMEZ VINTANED ${ }^{1}$, \\ Javier ÁLVARO', Rodolfo GOZALO², Teodoro PALACIOS ${ }^{3}$ y Klaus \\ $S D Z U Y^{4}$ \\ I Depto. de Geología (Área de Paleontología). Facultad de Ciencias. Universidad de Zaragoza. 50009-Zaragoza. \\ 2 Depto. de Geología. Facultad de Ciencias Biológicas. Universidad de Valencia. 46100-Burjasot (Valencia). \\ ${ }^{3}$ Depto. de Biología y Producción Vegetal (Área de Paleontología). Facultad de Ciencias. Universidad de Extremadura. 08071 - \\ Badajoz. \\ ${ }^{4}$ Institut für Paliaontologie. Universität Würzburg. 97070 Würzburg (Alemania).
}

\begin{abstract}
Liñán, L., Villas, E., Gámez-Vintaned, J.A., Álvaro, J., Gozalo, R., Palacios, T. y Sdzuy, K. 1996. Síntesis paleontológica del Cámbrico y Ordovícico del Sistema Ibérico (Cadenas Ibéricas y Cadenas Hespéricas) [Paleontological synthesis of Cambrian and Ordovician systems from Iberian Range (Iberian Chains and Hesperic chains) Revista Española de Paleontología, $\mathbf{N}^{\circ}$ Extraordinario, 21-32. ISSN 0213-6937.
\end{abstract}

\begin{abstract}
The information on systematic palaeontology is analysed and incorporated within global charts together with the lito- and chronostratigraphic units of the Cambrian-Ordovician succession from the Iberian and Hesperian Chains. The biostratigraphical units define in these regions are exposed together with a revision of their geographical area of application. Finally we indicate the problems that have not been solved yet.
\end{abstract}

Keywords: Iberian Cordillera, Cambrian, Ordovician, Trilobites, Brachipods, Echinoderms, Graptolites, Bivalves, Conodonts, Ichnofossils, Palinomorphs.

\section{RESUMEN}

Se analizan los datos de paleontología sistemática existentes en la bibliografía incorporándolos dentro de un esquema global junto a las unidades lito y cronoestratigráficas del Cámbrico y Ordovícico de las Cadenas Ibéricas y las Cadenas Hespéricas. Se presentan las diferentes unidades bioestratigráficas definidas en estas regiones y se revisa su área geográfica de aplicación. Finalmente se refieren los problemas aún no resueltos.

Palabras clave: Cordillera Ibérica, Cámbrico, Ordovícico, Trilobites, Braquiópodos, Equinodermos, Graptolitos, Bivalvos, Conodontos, Icnofósiles, Palinomorfos.

\section{INTRODUCCIÓN}

La Cordillera Ibérica o, más propiamente, el Sistema Ibérico, término este último empleado ya por Bory de SaintVicent en la primera mitad del siglo pasado (Verneuil y Lorière, 1854), es una alineación montañosa de dirección NO-SE que se extiende desde las inmediaciones del mar Cantábrico hasta las del Mediterráneo, configurando junto a los Pirineos y al Sistema Costero Catalán, una estructura montañosa triangular en el NE español, en cuyo interior se sitúa la Depresión del Ebro.

Los afloramientos paleozoicos constituyen los núcleos de tres partes orográficas bien delimitadas: La Sierra de la Demanda al Norte, las Cadenas Ibéricas en el centro y las Cadenas Hespéricas al Sur. Estos dos últimos conjuntos montañosos fueron establecidos por Dereims (1898).

Los terrenos paleozoicos de las Cadenas Ibéricas se presentan como dos alineaciones de afloramientos de dirección NO-SE que están aislados del Macizo Hespérico y separados entre sí por la depresión terciaria de Calatayud-Teruel. Geológicamente han sido asimilados a las Zonas Cantábrica y Astur-Occidental Leonesa del Macizo Hespérico, de las que presumiblemente son prolongación (Gozalo y Liñán, 1988). Los terrenos cámbricos y ordovícicos representan más de las tres cuartas partes de los afloramientos paleozoicos de las Cadenas Ibéricas, y constituyen una de las pocas sucesiones estratigráficas continuas que tenemos en la Península Ibérica de estos periodos. Los terrenos paleozoicos de las Cadenas Hespéricas se presentan como un rosario de afloramientos discontinuos en donde no están representados los terrenos cámbricos. Geológicamente han sido asimilados a la prolongación de la parte occidental de la Zona Astur-Occidental Leonesa (Fig. 1).

Las primeras referencias a fósiles cámbricos de las Cadenas Ibéricas fueron de trilobites, ya citados por Verneuil (1862) en Murero y por Verneuil y Lartet (1863) entre Beratón y Borobia. Los primeros fósiles ordovícicos encontrados en las Cadenas Hespéricas fueron también trilobites, citados 


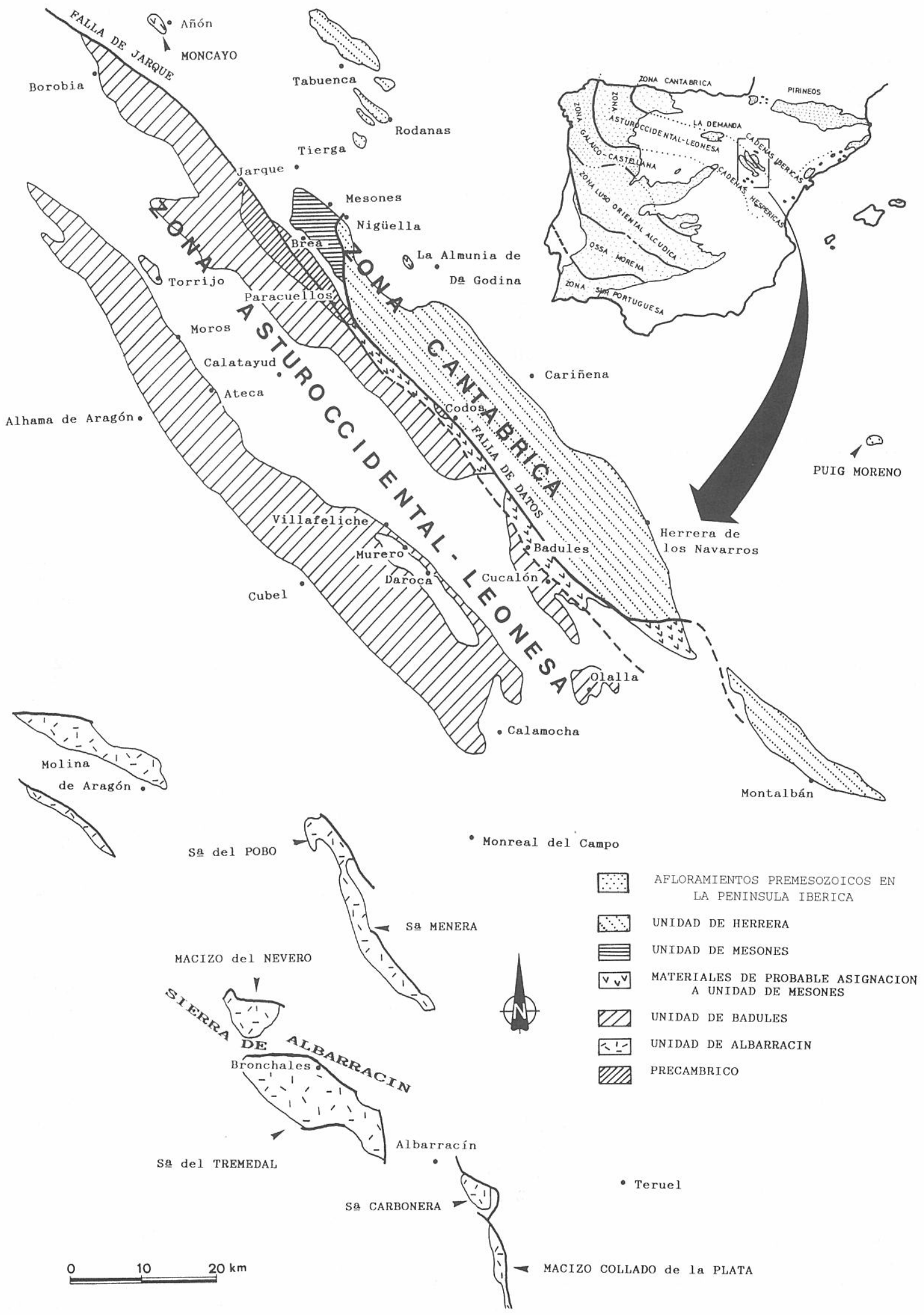

Figura 1. Localización geográfica y geológica de los afloramientos cámbricos y ordovícicos de la Cordillera Ibérica, y su correlación con las Zonas geológicas del Macizo Ibérico. (Liñán et al., 1991). 
por Torrubia (1754) como "especie de cangrejos"; mientras en las Cadenas Ibéricas fueron pistas fósiles descubiertas en 1873 por Donayre. Con ello se inició una primera época de citas taxonómicas de trilobites, pistas fósiles y braquiópodos donde, en general, existían pocas figuraciones, salvo las de pistas de Donayre o las de trilobites del Cámbrico en Mallada (1875) y del Ordovícico en Torrubia. En esta época podemos incluir los trabajos de Palacios (1890, 1893), Dereims (1898) y Lotze (1929), éste con determinaciones paleontológicas de los esposos Richter, época en la que se amplía el número de localidades que contienen fósiles cámbricos y ordovícicos, cada vez taxonómicamente más variados y biostratigráficamente más precisos.

Una segunda época abarca las dos últimas décadas de la primera mitad del presente siglo donde ya se figuran y describen específicamente los taxones. Hernández Sampelayo (1935) estudia los trilobites, braquiópodos, equinodermos y pistas fósiles de España, donde incluye los de las Cadenas Ibéricas, que serían estudiados con más detalle por Meléndez (1944) y Meléndez y Hevia (1947), y revisados por Badillo (1959).

La tercera época se va a caracterizar por estudios sistemáticos especializados que han servido de base para esta síntesis y que comentaremos más adelante en el apartado de paleontología.

El objetivo de este trabajo es dar una visión moderna del estado actual de los estudios paleontológicos del Cámbrico y del Ordovícico del Sistema Ibérico, analizando los problemas resueltos y aquéllos que están aún por resolver. Para ello, se ha emprendido la recopilación de los trabajos paleontológicos previos, el análisis de la ingente información y su exposición sintética mediante gráficos divididos por unidades cronoestratigráficas y litoestratigráficas donde se representa el contenido taxonómico y la distribución estratigráfica de los grupos paleontológicos, cuestión ésta que no había sido realizada anteriormente. De este modo, se dispone de un banco de datos sencillo donde ir incorporando los nuevos hallazgos y modificando los antiguos. Durante el análisis de la información se han eliminado aquellos datos no seguros y gran parte de datos no confirmados por carecer de figuraciones, prefiriendo la calidad de la información a la cantidad que puede ser ampliada en años sucesivos.

\section{ESTRATIGRAFÍA}

En las Cadenas Ibéricas, la sucesión estratigráfica del Cámbrico y Ordovícico es conocida a grandes rasgos desde el trabajo de Lotze (1929), pero la definición formal de las formaciones estratigráficas ha sido un proceso largo que sólo ha culminado en época reciente, debido sobre todo a la complejidad tectónica, al gran espesor de materiales acumulados (más de cinco mil metros), a los frecuentes y recurrentes cambios verticales de litofacies, y al inadecuado conocimiento paleontológico (Figs. 2 y 3). Lotze (1929) define la litoestratigrafía del Cámbrico Inferior (Formaciones Bámbola, Embid, Jalón, Ribota, Huérmeda y Daroca). Liñán et al. (1992) redefinen la litoestratigrafía del tránsito Cámbrico Inferior y Medio (Grupo Mesones, constituido por las Formaciones Valdemiedes, Mansilla y Murero) que presentaban numerosos problemas de sinonimias, conceptualmente distintas. Álvaro
(1995) define formalmente las unidades litoestratigráficas del Cámbrico Medio y tránsito al Cámbrico Superior (Formaciones Borobia, Valdeorea, Torcas, Encomienda y Valtorres) incluidas en el Grupo Acón definido por Schmitz (Acón Schichten; 1971). Previamente, Wolf (1980) había abordado la definición de las Formaciones del tránsito Cámbrico Superior-Ordovícico (Formaciones Valconchán, Borrachón, Dere y Santed) a las que se añadiría la Cuarcita Armoricana. Villas (1983, 1985) complementaría la estratigrafía con la definición de las Formaciones Castillejo (miembros Marité, Alpartir y Sierra) y Fombuena (miembros Piedra del Tormo y Huerva). Finalmente, los últimos materiales del Ordovícico están representados por las formaciones Calizas de Cistideos (Dereims, 1898), subdividida en cuatro miembros por Hammann (1992), y Pizarras de Orea (Greiling, en Sacher, 1966).

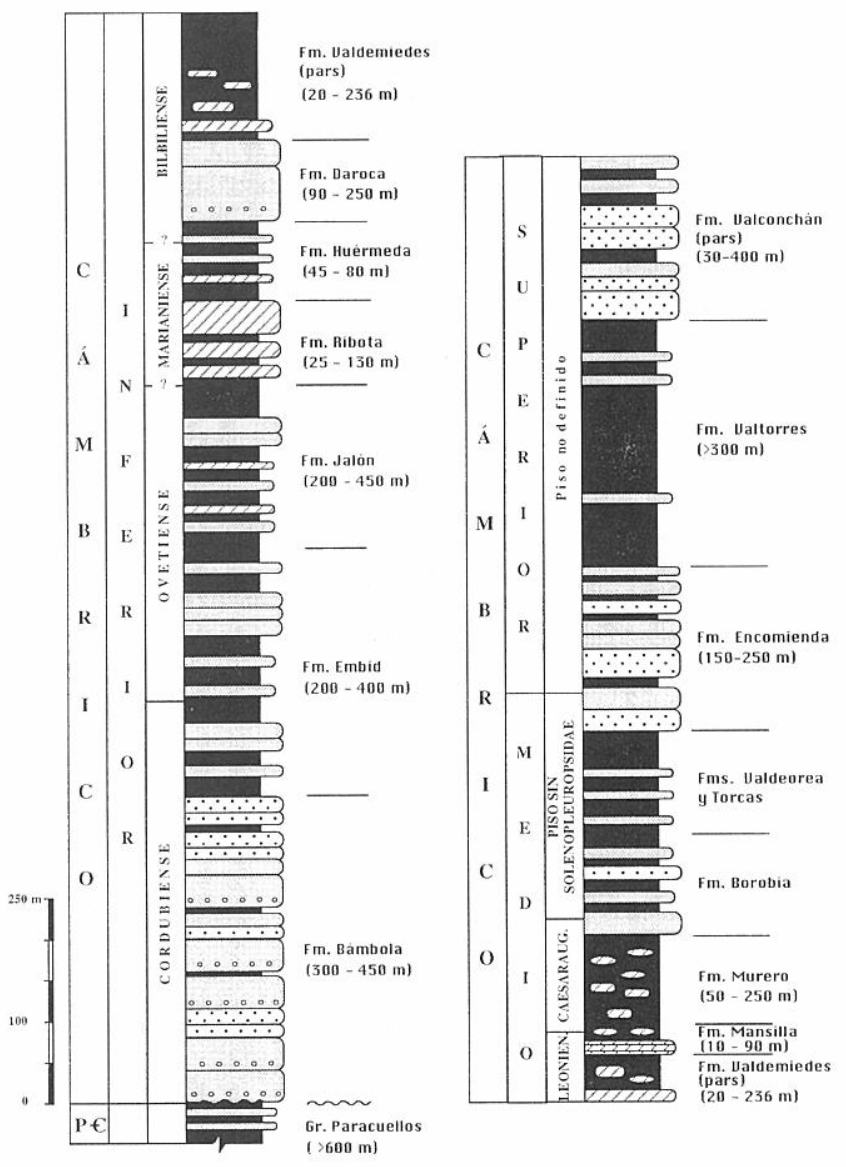

Figura 2. Columna estratigráfica sintética del Cámbrico de las Cadenas Ibéricas, basada en la nomenclatura de Lotze (1929), Liñán et al. (1992), Álvaro (1995) y Wolf( 1980).

El límite Cámbrico-Ordovícico fue situado por Wolf (1980) en el techo de la Formación Valconchán, basándose fundamentalmente en la presencia, en el "nivel de Oryctoconus", del trilobites Pagodia (Wittekindtia) sp., que indicaría ya una edad Tremadoc. Sin embargo, Shergold y Sdzuy (1991) proponen datar este nivel como Cámbrico Superior, atendiendo a la presencia por encima de él de asociaciones de trilobites, no descritas, afines a faunas mejicanas del Cám- 
brico tardío; y siguiendo las últimas tendencias que sitúan el límite Cámbrico-Ordovícico en la base de la zona de conodontos de Cordylodus lindstromi. Villas et al. (1995), teniendo en cuenta la indefinición actual de la Comisión Internacional de Estratigrafía de la IUGS sobre la posición del citado límite (Norford, 1988), proponen no cerrar la cuestión y situar simplemente el "nivel de Oryctoconus" en la transición Cámbrico-Ordovícico. Esta datación imprecisa había sido propuesta por Havlíček y Josopait (1972), y es la seguida en el presente trabajo.

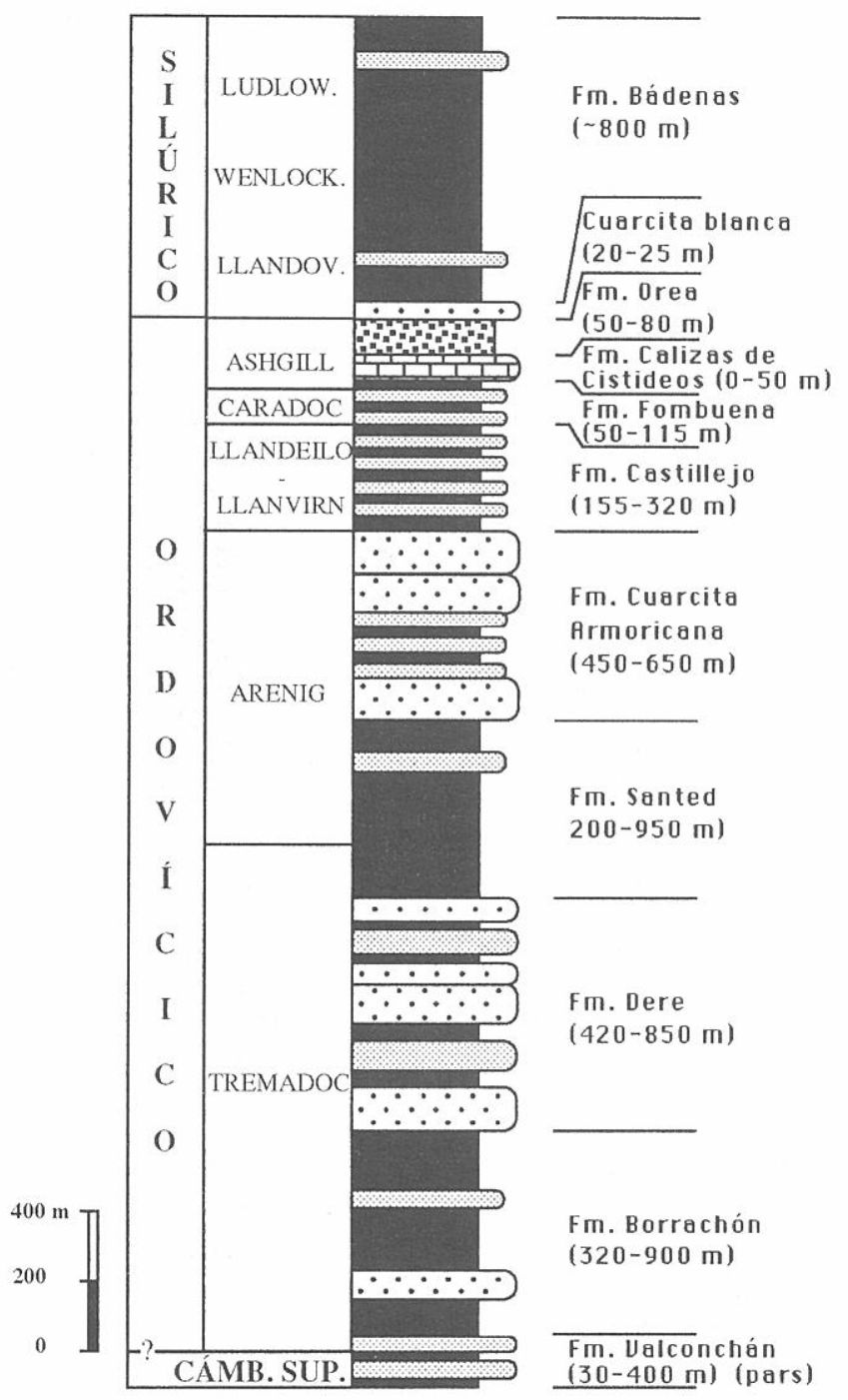

Figura 3. Columna estratigráfica sintética del Ordovícico de las Cadenas Ibéricas, basada en la nomenclatura de Wolf (1980), Villas (1983, 1985), Dereims (1898), Hammann (1992) y Greiling (en Sacher 1966).

En las Cadenas Hespéricas, la Cuarcita Armoricana es la formación más antigua identificada con claridad. Sobre ella se desarrolla una sucesión fundamentalmente terrígena que guarda un fuerte paralelismo con la de las Cadenas Ibéricas. Para esta sucesión, Villena (1976) propuso una serie de unidades litoestratigráficas formales, algunas de las cuales siguen sien- do utilizadas en la actualidad. Es el caso de la Formación Grauwackas de La Venta, de edad Llanvirn-Llandeilo, correlacionable a grandes rasgos con la Formación Castillejo de las Cadenas Ibéricas, y el caso del miembro superior de las Calizas de El Pobo, denominado Calizas del Cabezo, al que parece más adecuado darle un rango de formación, y que es correlacionable con las Calizas de Cistideos de edad Ashgill. El miembro inferior de las Calizas del Pobo introducido por Villena (1976) como las Cuarcitas de Colmenarejos, así como el Miembro Areniscas de Tordesilos, considerado por el mismo autor como un cambio lateral de facies de las Calizas del Cabezo, son abandonados. Gutiérrez Marco (1986) propone utilizar en su lugar dos unidades sucesivas: la Formación Cuarcitas de la Serretilla (Riba, 1982) y las "Capas de Bronchales” (Portero, 1983; Hernández y Olivé, 1983), correlacionables aproximadamente con la Formación Fombuena de las Cadenas Ibéricas. El Ashgill terminal está representado también aquí por las Pizarras de Orea, que Greiling (en Sacher, 1966) define en Sierra Nevera.

\section{PALEONTOLOGÍA}

Trataremos en este apartado los grupos de trilobites, braquiópodos, equinodermos, pistas fósiles, acritarcos, algas calcáreas, graptolitos, bivalvos y conodontos, en términos de contenido taxonómico, distribución estratigráfica, grado de conocimiento e interés geológico en la región. Para la cronoestratigrafía del Cámbrico utilizaremos los pisos regionales según la revisión de Liñán, Perejón y Sdzuy (1993).

\section{Los Trilobites}

En la época más moderna, los trilobites del Cámbrico fueron estudiados por Richter y Richter (1948) quienes describen los primeros hallazgos del Cámbrico Inferior en la Formación Ribota. Los trabajos de Sdzuy (1958, 1961, 1987) van a suponer un importante avance en el conocimiento de los trilobites del Cámbrico Inferior y Medio (Figs. 4 y 5) y la consideración de Aragón como una de las regiones básicas para el establecimiento de la bioestratigrafía del Cámbrico (Fig. 6); estos estudios serían después complementados con la monografía de Liñán y Gozalo (1986), que abarca 25 géneros y 58 especies, y con los trabajos de Gámez et al. (1991), Álvaro, Gozalo y Liñán (1993), Gozalo et al. (1993) y Gozalo, Liñán et al. (1993). Los trilobites del Cámbrico Superior fueron tratados por Shergold y Sdzuy (1991), (Fig. 8), y los del Ordovícico por Hammann (1983) en la Formación Castillejo (Llanvirn-Llandeilo), (Fig. 10), y Owen y Hammann (1990) en la Formación Calizas de Cistideos (Ashgill). En esta última, Hammann (1992) describe 34 géneros (2 nuevos) y 43 especies (12 nuevas), (Figs. 12 y 13).

Los primeros trilobites del Cámbrico Inferior de la Cadenas Ibéricas son bastante recientes (Ovetiense Superior) en relación a los registrados en otras partes de España. Ello pudo ser debido a la proximidad de este área paleogeográfica a la línea de costa, lo que no favoreció el registro de estos organismos hasta muy avanzado el Cámbrico Inferior (Sdzuy y Liñán, 1993). El registro estratigráfico está muy condicionado por los efectos de la regresión Cerro del Hierro en el 


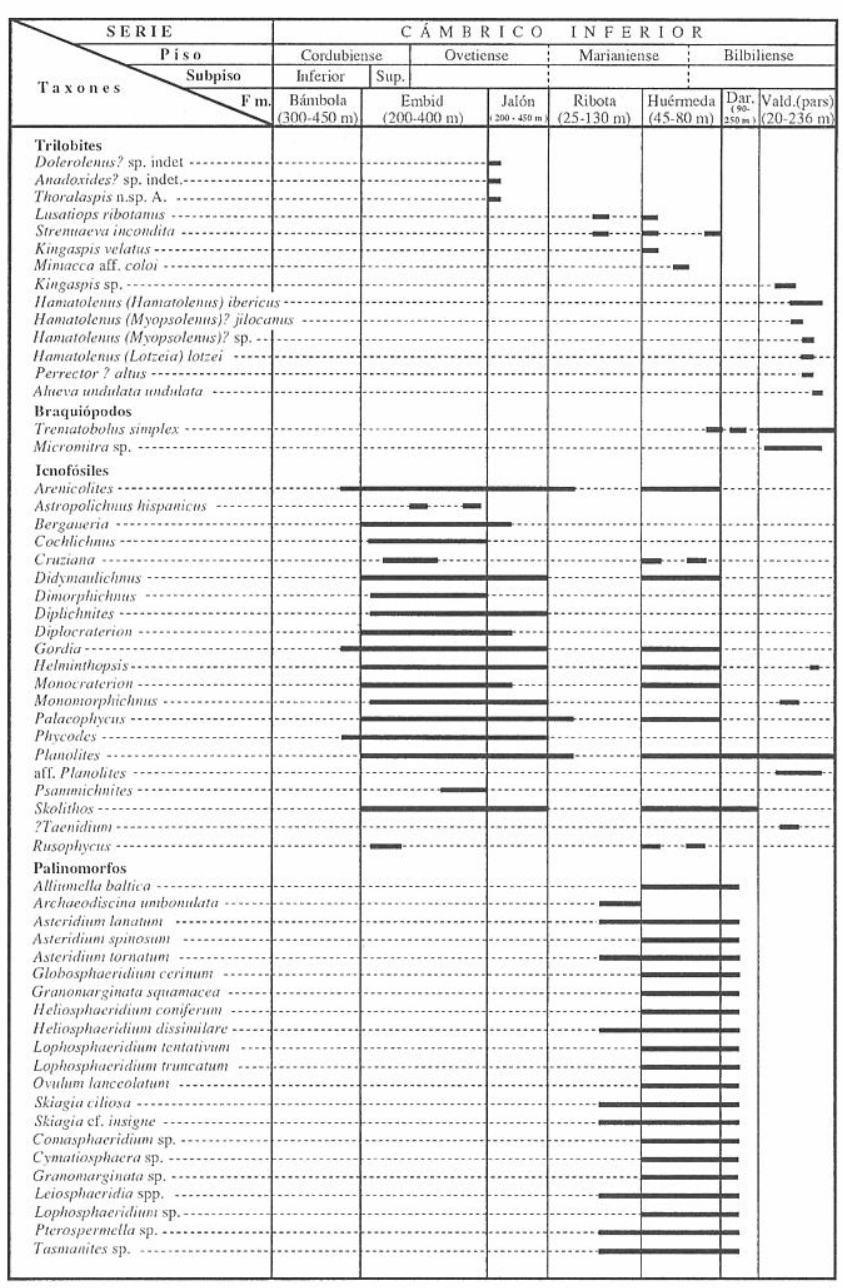

Figura 4. Distribución estratigráfica de los trilobites, braquiópodos, icnofósiles y palinomorfos del Cámbrico Inferior de las Cadenas Ibéricas. Basada, respectivamente, en datos de: Richter (1948), Lotze und Sdzuy (1961), Sdzuy (1971a, 1987) y Liñán y Gozalo (1986); Liñán y Mergl (1986); Seilacher (1970), Valenzuela et al. (1990), Gámez et al. (1991), Gámez Vintaned y Mayoral Alfaro (1992), Álvaro, Liñán et al. (1993) y Gámez Vintaned (inéditos); y Palacios (inéditos).

Ovetiense Superior (capas rojas de medios litorales depositadas en un contexto regresivo bajo condiciones áridas; Formación Jalón) y de la regresión Daroca en el Bilbiliense Inferior (areniscas y conglomerados de la Formación Daroca). Ambas regresiones, definidas por Liñán y Gámez-Vintaned (1993), son la causa principal de que el registro de trilobites no sea completo en el Cámbrico Inferior de las Cadenas Ibéricas. En el tránsito Cámbrico Inferior-Medio disponemos de uno de los mejores registros mundiales y existe un alto conocimiento de su registro taxonómico. Por contra, el Cámbrico Medio, a pesar de contener uno de los mejores registros de trilobites, no está suficientemente conocido, debido a la inserción en el Leoniense de un depósito carbonatado bioclástico de alta energía, dolomitizado en muchas localidades, y a la regresión experimentada al final de Caesaraugustiense que restringe la presencia de trilobites, tan frecuente hasta entonces, y que será ya esporádica hasta el Ordovícico. En el

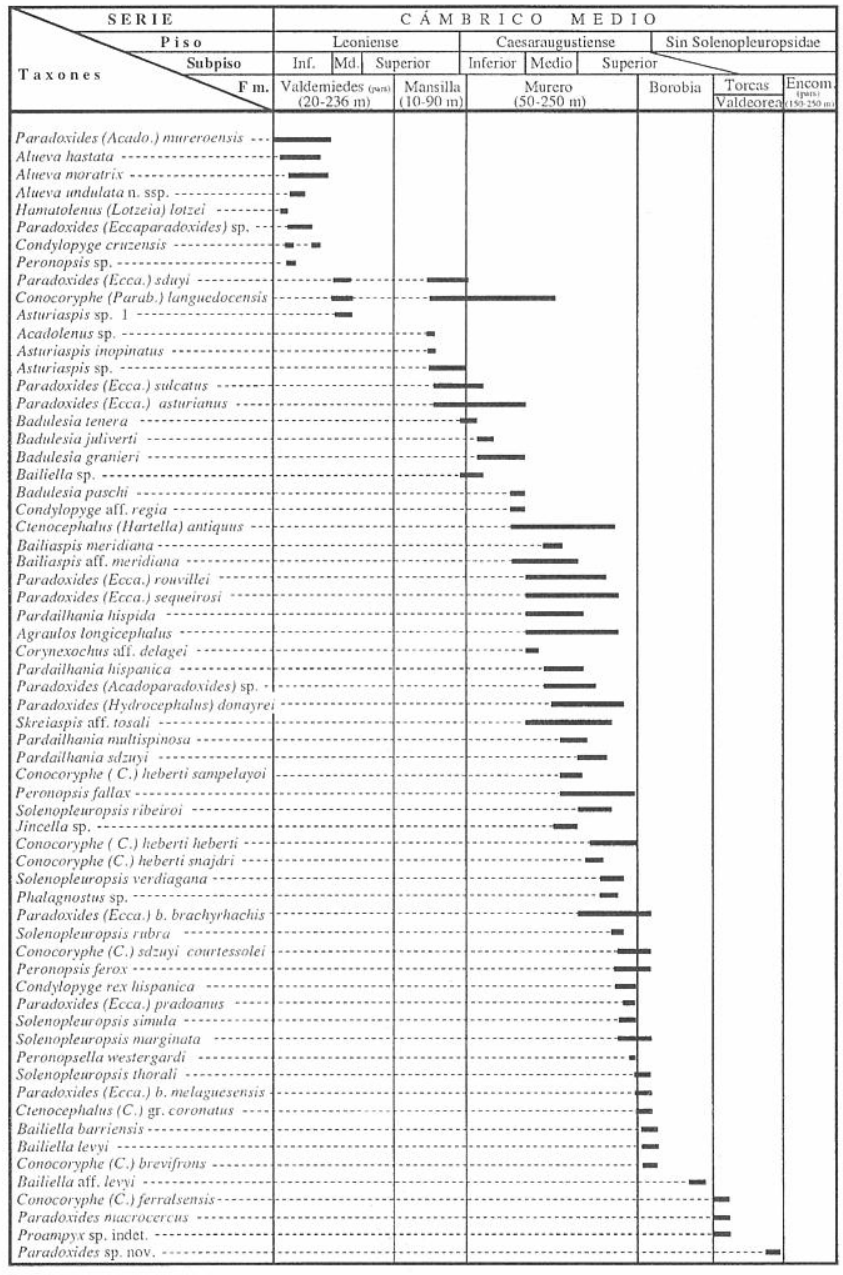

Figura 5. Distribución estratigráfica de los trilobites del Cámbrico Medio en las Cadenas Ibéricas. Según datos de Lotze y Sdzuy (1961), Liñán y Gozalo (1986), Liñán, FernándezNieto et al. (1993), Gámez et al. (1991), Álvaro , Gozalo y Liñán (1993) y Gozalo et al. (1993).

Tremadoc son frecuentes las facies de trilobites, que aún están siendo estudiados (Fig. 9). A partir del Llanvirn los trilobites aumentan en número de taxones hasta alcanzar su máximo en el Ashgill, abundancia que se corresponde con un periodo de mejora climática.

\section{Los Braquiópodos}

Las primeras citas de braquiópodos fueron probablemente las de Palacios (1893) y Dereims (1898) del Cámbrico Medio, pero con seguridad el primero en figurarlos es Hernández Sampelayo (1935). Los braquiópodos son un grupo poco frecuente en la región que nos ocupa hasta la transición Cámbrico Inferior-Medio donde se hacen extraordinariamente frecuentes (Fig. 7), después de la regresión Daroca, en las Formaciones Valdemiedes, Mansilla y Murero, pero con poca variedad taxonómica (Vogel, 1962; Havlíček y Kříž, 1978; Mergl y Liñán, 1986) en comparación con los trilobites. En la transición Cámbrico-Medio Superior 


\begin{tabular}{|c|c|c|c|c|}
\hline $\begin{array}{l}\text { Siste- } \\
\text { ma }\end{array}$ & Serie & Piso & Subpiso & Biozona \\
\hline \multirow{17}{*}{$\begin{array}{l}C \\
\text { Á } \\
M \\
B \\
R \\
1 \\
C \\
O\end{array}$} & \multirow{17}{*}{$\begin{array}{l}M \\
E \\
D \\
1 \\
O\end{array}$} & \multicolumn{2}{|c|}{ Sin Solenopleuropsidae } & \\
\hline & & \multirow{13}{*}{$\begin{array}{c}\text { CAESAR- } \\
\text { AUGUSTIENSE }\end{array}$} & \multirow{6}{*}{ Superior } & S. thorali+S. marginata \\
\hline & & & & S. simula \\
\hline & & & & S. verdiagana+S. rubra \\
\hline & & & & S. ribeiroi+S. verdiagana \\
\hline & & & & S. ribeiroi \\
\hline & & & & P. sdzuyi+S. ribeiroi \\
\hline & & & \multirow{3}{*}{ Medio } & P. multispinosa \\
\hline & & & & P. hispanica \\
\hline & & & & P. hispida \\
\hline & & & \multirow{4}{*}{ Inferior } & B. granieri+B. paschi \\
\hline & & & & B. granieri+B. juliverti \\
\hline & & & & B. tenera \\
\hline & & & & B. sp. A \\
\hline & & \multirow{3}{*}{ LEONIENSE } & Superior & Acadolenus sp. sp. \\
\hline & & & Medio & C. (C.) ovata \\
\hline & & & Inferior & P. (A.) mureroensis \\
\hline & INF. & BILBILIENSE & Superior & H. $(\mathrm{H}$.$) ibericus$ \\
\hline
\end{tabular}

Figura 6. Biozonación de trilobites propuesta para el Cámbrico Medio del sur de Europa basada en la sucesión presente en las Cadenas Ibéricas. Según Sdzuy (1917b), Liñán y Gozalo (1986) y Liñán, Fernández-Nieto et al. (1993).

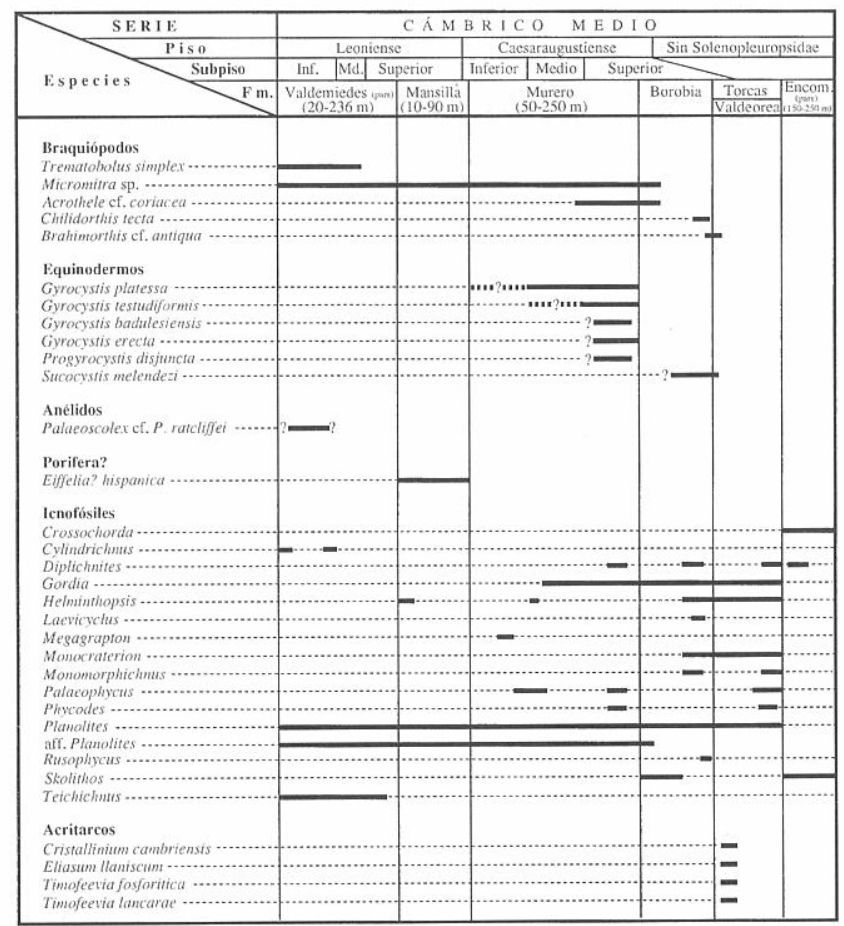

Figura 7. Distribución estratigráfica de los braquiópodos, equinodermos, anélidos, ¿poríferos?, icnofósiles, y acritarcos del Cámbrico Medio de las Cadenas Ibéricas. Basada, respectivamente, en datos de: Liñán y Mergl (1986); Friedrich (1993); Conway Morris y Robison (1986); Gámez et al. (1986); Gámez et al. (1991), Gámez Vintaned y Mayoral Alfaro (1992) y Gámez Vintaned (inéditos); y Gámez et al. (1991). aparecen concentrados en niveles (Havlícek y Josopait, 1972), pero su máxima expansión la alcanzan en el Ordovícico, donde destacan los trabajos de Villas (1985, 1992) sobre más de cincuenta especies del Llandeilo-Ashgill (Fig. 14), superando por primera vez, cualitativa y cuantitativamente, a los trilobites. Ello ha permitido proponer una biozonación de braquiópodos para el Ordovícico medio - superior (Villas, 1985) que se ha mostrado útil para el ámbito Mediterráneo (Leone et al., 1991), y sobre la que actualmente se están realizando algunas precisiones (Villas et al., 1995).

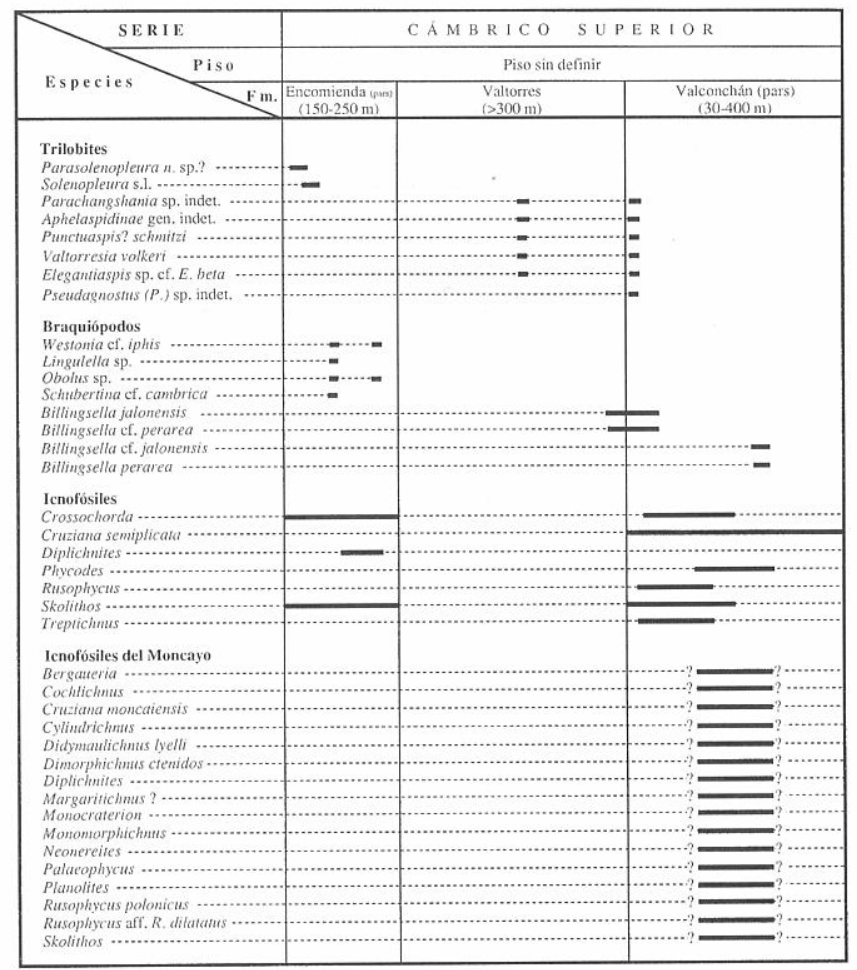

Figura 8. Distribución estratigráfica de los trilobites, braquiópodos e icnofósiles del Cámbrico Superior de las Cadenas Ibéricas. Según datos, respectivamente, de Shergold y Sdzuy (1991); Havliček y Josopait (1972); y Wolf (1980) y Gámez-Vintaned (1995).

\section{Los Equinodermos}

Es un grupo bastante frecuente en las Cadenas Ibéricas en relación con otras regiones pero que está desigualmente estudiado. Los primeros restos identificables aparecen en la parte alta del Cámbrico Inferior (Bilbiliense) dentro de la Formación Valdemiedes y se refieren a Carpoideos y Edrioasteroideos. En el Cámbrico Medio son muy frecuentes aunque lo más corriente es encontrar las placas desunidas; destaca el trabajo de Schroeder (1973), cuyo material probablemente proceda de la Formación Murero y del Grupo Acón, y el de Friedrich (1993). En el Ordovícico hay que destacar los trabajos de Meléndez (1959), Chauvel et al. (1975), y Chauvel y Le Menn (1979), que estudian principalmente los cistideos, pero también algunos crinoideos y blastoideos procedentes de las facies margosas de la Formación 
Calizas de Cistideos (Fig. 10). Finalmente, Gutiérrez Marco et al. (1991) estudian los cistideos y blastoideos del Llandeilo-Caradoc en ambas cadenas de la cordillera.

\begin{tabular}{|c|c|c|c|c|c|}
\hline \multirow{3}{*}{ Taxones } & $\epsilon ?$ & \multicolumn{3}{|c|}{ TREMADOC } & AREN I G \\
\hline & & \multicolumn{2}{|c|}{ Pisos sin definir } & \multicolumn{2}{|c|}{ Pisos sin definir } \\
\hline & $\begin{array}{l}\text { Valce } \\
\text { paras } \\
\end{array}$ & $\begin{array}{l}\text { Borrachón } \\
(320.900 \mathrm{~m})\end{array}$ & $\begin{array}{c}\text { Dere } \\
\begin{array}{c}\text { Dere } \\
\text { (40.850 } \mathrm{m})\end{array}\end{array}$ & $\begin{array}{l}\text { Santed } \\
(200.050 \mathrm{~m}\end{array}$ & 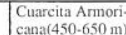 \\
\hline Equinodermos & & & & & \\
\hline $\begin{array}{l}\text { Trilobites } \\
\text { The }\end{array}$ & & & & & \\
\hline 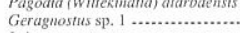 & & & & & \\
\hline 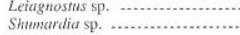 & & & & & \\
\hline 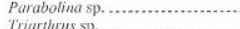 & & $=$ & & & \\
\hline Angelina sp. ........................ & & $=$ & & & \\
\hline 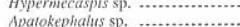 & & & & & \\
\hline Dikelokephatina sp. 2 ............. & $\cdots$. & $\cdots \cdots \cdots=$ & & & \\
\hline Dikelokephlatina sp. 2 _.............. & & ……… & - & & \\
\hline 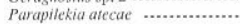 & & & & & \\
\hline Prionocheilus cf. langucdociensis & & & & $=$ & \\
\hline 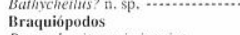 & & & & & \\
\hline 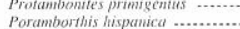 & -1. & & & & \\
\hline 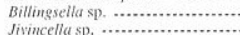 & $=$ & & $-\pi$ & & \\
\hline 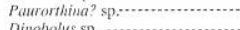 & & & & & \\
\hline Acritarcas & & & & & - \\
\hline 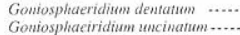 & & & & & \\
\hline 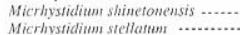 & & & & & \\
\hline 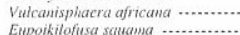 & & & & & \\
\hline 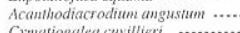 & & & & & \\
\hline 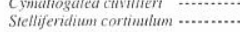 & & & & - & \\
\hline 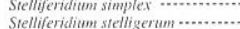 & $\cdots$ & & & & \\
\hline 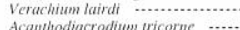 & & & & & \\
\hline 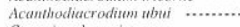 & $\cdots$ & & & & \\
\hline 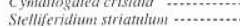 & & & & & \\
\hline Acanthodiacroditum remadocum & ..... & & & - & \\
\hline 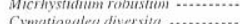 & ... & & & & \\
\hline 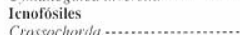 & & & & & \\
\hline Cruziama furcifera …................... & - & $=$ & $-\cdots \cdots$ & - & \\
\hline 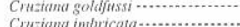 & & & & & \\
\hline Cruzituma rugosa.... & $\cdots .$. & & & - & - - \\
\hline $\begin{array}{l}\text { Craziama semiplicata } \\
\text { - }\end{array}$ & - & & & & $-\pi$ \\
\hline Dodalut & & & & & $=$ \\
\hline Dictrodora .... & $\cdots$ & & & & $=$ \\
\hline 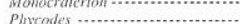 & $\cdots !$ & ........ & …...... & & ….. \\
\hline Protovirgutut & & & & & $-m+2$ \\
\hline 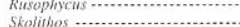 & & & & & \\
\hline & & & & & \\
\hline
\end{tabular}

Figura 9. Distribución estratigráfica de los equinodermos, trilobites, braquiópodos, acritarcos e icnofósiles citados y/o descritos en la Cordillera Ibérica en el Ordovícico temprano (según Hammann, 1974, 1983; Hammann et al. 1982; Havliček y Josopait, 1972; Shergold y Sdzuy, 1991; Wolf, 1980)

\section{Los Graptolitos y Bivalvos}

Tras los estudios pioneros de Philippot y Riba (1952 a y b) sobre los graptolitos del Llanvirn de las Cadenas Hespéricas, Gutiérrez Marco (1986), en su estudio sobre los graptolitos del Ordovícico español, describe en la cordillera 7 géneros y 8 especies, 4 de ellas nuevas, pero al ser un trabajo inédito se trata de especies con nomen nudum. Además, Gutiérrez Marco (1986) da listas de otros grupos fósiles en el Ordovícico del Sistema Ibérico, complementado los datos de los autores citados anteriormente, como es el caso de los trilobites y los braquiópodos.

Babin y Gutiérrez Marco (1991) describen 9 especies de bivalvos en su estudio sobre este grupo en el Llanvirn-Llandeilo español (Fig. 11).

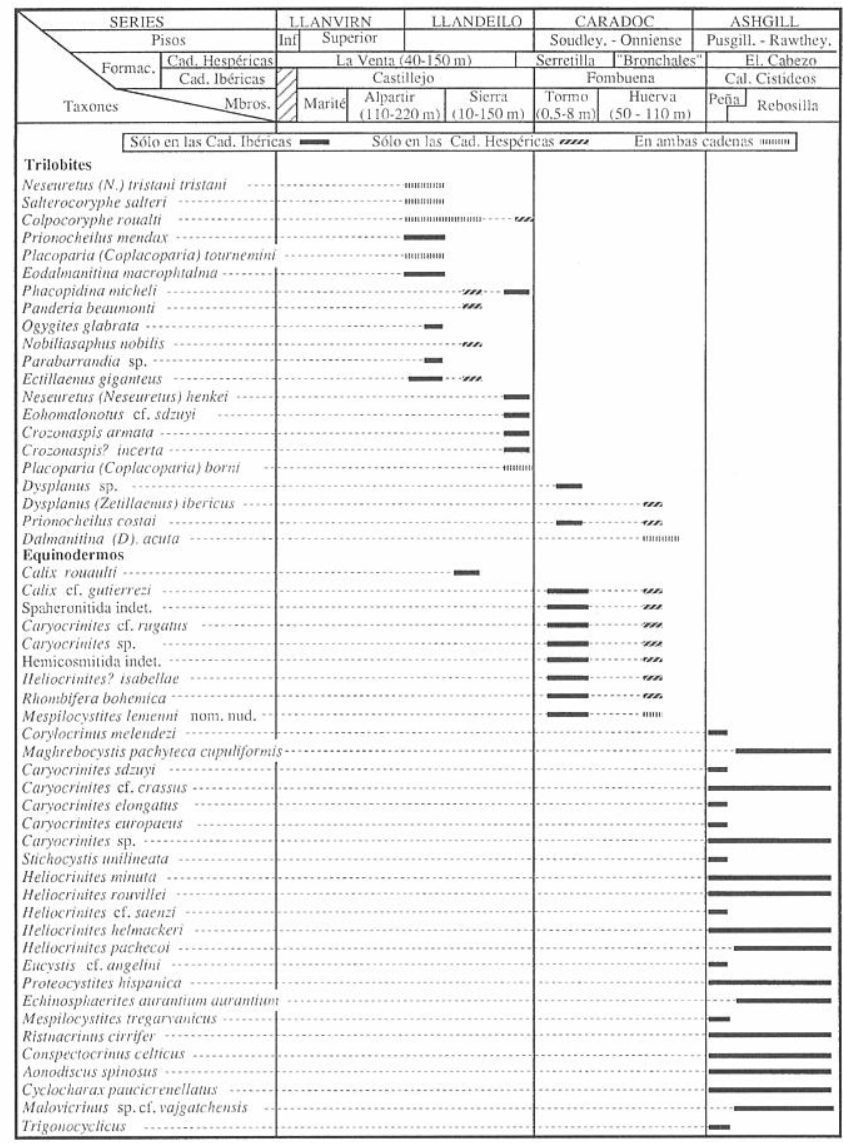

Figura 10. Distribución estratigráfica de los trilobites, cistideos, crinoideos y blastoideos citados y/o descritos en el Ordovícico medio y superior de la Cordillera Ibérica (según Hammann, 1983; Gutiérrez Marco, 1986, 1981; Chauvel et al. 1975; y Chauvel y Le Menn, 1979).

\section{Los Conodontos}

Carls (1975) dio una lista de 31 especies de conodontos procedentes de las facies biomicríticas de la Formación Calizas de Cistideos (Fig. 11), con la que confirmaba la edad Ashgill de esta unidad. La pobreza en horizontes calcáreos del Cámbrico-Ordovícico de la región hace que, aparte de aquéllas, sólo se conozca una especie más en la sucesión estudiada; ésta procede de unas pequeñas intercalaciones calcáreas en el Miembro Peña del Tormo de la Formación Fombuena (Carls, 1975).

\section{Las pistas fósiles}

Las pistas fósiles aparecen a lo largo de todo el registro estratigráfico, con una menor conservación en las facies carbonatadas. Las del Cámbrico Inferior han sido abordadas por Seilacher (1970), Valenzuela et al. (1990), Gámez et al. (1991), Álvaro, Liñán et al. (1993) y Pillola et al (1994). Las de la transición Cámbrico Inferior y Medio por Gámez Vintaned y Mayoral Alfaro (1992) y las del Cámbrico Superior-Ordovícico por Kolb y Wolf (1979) y Gámez-Vintaned (1995). 


\section{Los Acritarcos}

Finalmente, los acritarcos han sido referidos recientemente por Gámez et al. (1991) en el Cámbrico Inferior y Medio, y por Wolf (1980) en el Ordovícico inferior (Figs. 4, 7 y 9). Hafenrichter (1980) estudió los acritarcos de la Formación Pizarras de Orea, determinando que indicaban ya una edad Silúrico basal; sin embargo, sus conclusiones cronoestratigráficas han sido cuestionadas por los problemas que plantea ese grupo en cuanto al tratamiento taxonómico y distribución estratigráfica (Robardet y Doré, 1988). De hecho, la Formación Orea es considerada como un registro de los fenómenos glaciales finiordovícicos que afectaron a la región, y datada como Hirnantiense.

\section{PROBLEMAS SIN RESOLVER}

En el Cámbrico, donde los estudios están muy avanzados, quedan aún importantes problemas no resueltos. Así, los trilobites del Cámbrico Inferior están mal conocidos y su estudio puede representar un buen paso para establecer correlaciones precisas entre el Norte, centro y Sur de España durante el Marianiense, y proponer una biozonación complementaria para los ecosistemas marinos someros y abrigados que comparar con la ya propuesta en el Sur y centro penin-

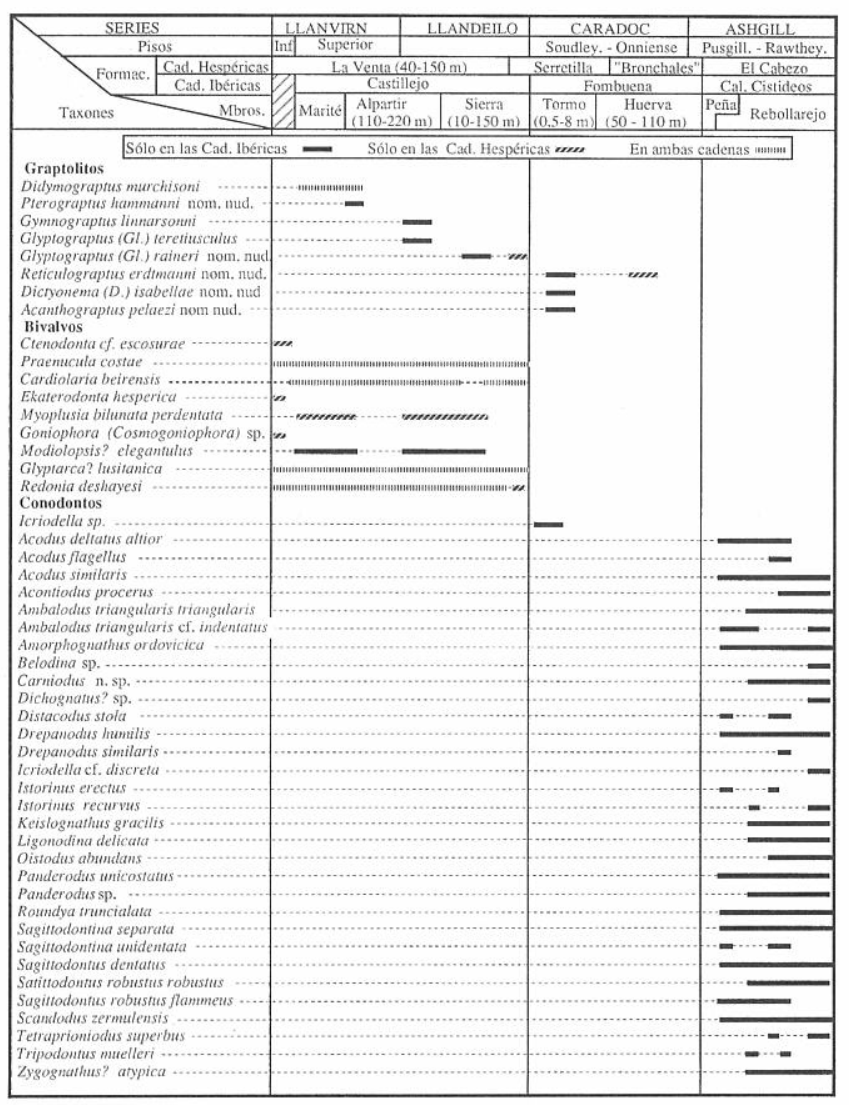

Figura 11. Distribución estratigráfica de los graptolitos, bivalvos y conodontos citados en el Ordovícico de la Cordillera Ibérica (según Gutiérrez Marco, 1986; Babin y Gutiérrez Marco, 1991; y Carls, 1975).

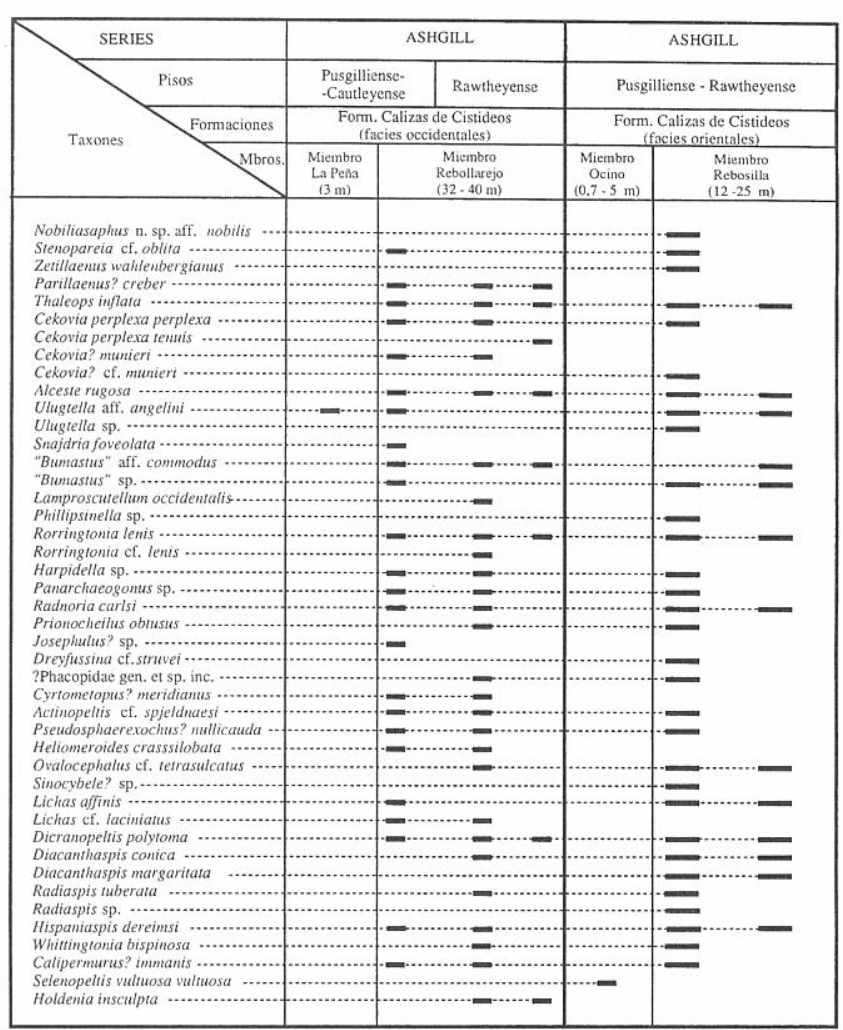

Figura 12. Distribución estratigráfica de los trilobites del Ashgill descritos en la Cordillera Ibérica (según Hammann, 1992).

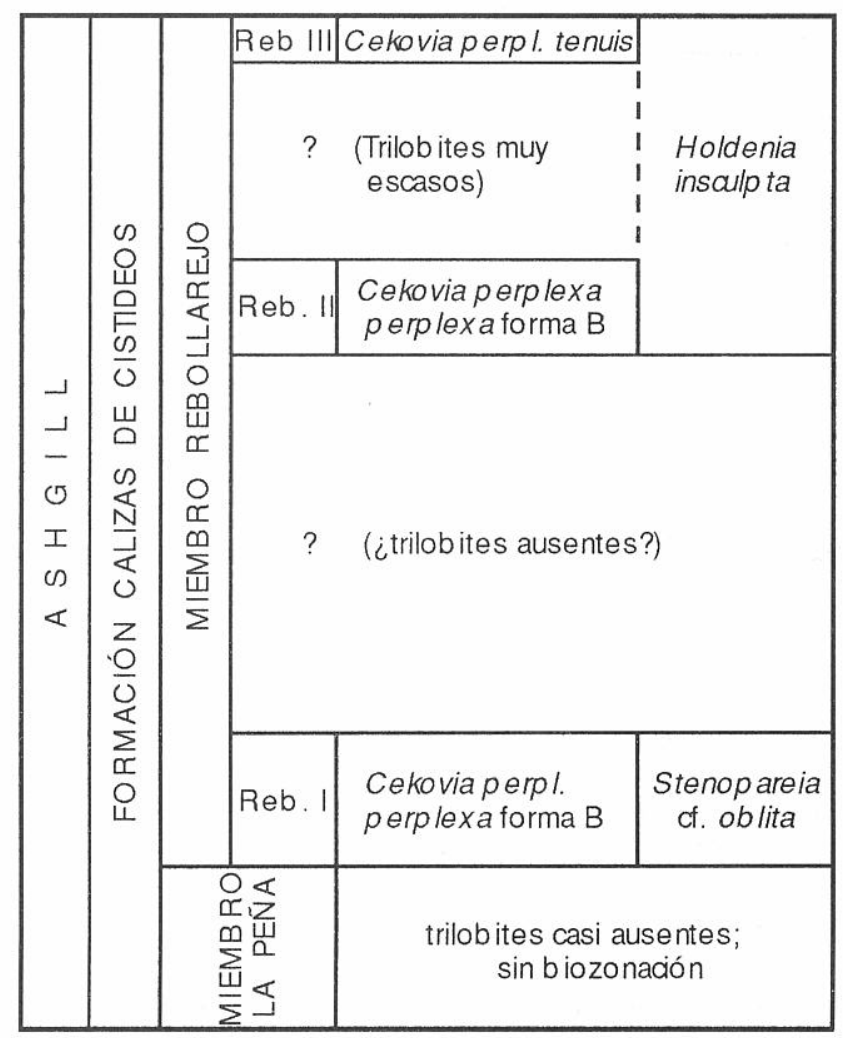

Figura 13. Biozonación con trilobites propuesta para el Ashgill de la Cordillera Ibérica (según Hammann, 1992). 
sular para ambientes más profundos. También tenemos probablemente la mejor representación paleontológica en España del piso sin Solenopleuropsidae, cuyo estudio, aún no realizado, será necesario abordar en el futuro.

\begin{tabular}{|c|c|c|c|c|c|c|}
\hline SERIES & LLAND & & $\begin{aligned} \text { CARA } \\
\text { Soudleyense - }\end{aligned}$ & $\begin{array}{ll}O C \\
O \text { Onniense }\end{array}$ & & $\begin{array}{l}\text { GGILL } \\
\text { Rawheyc }\end{array}$ \\
\hline $\int_{\text {Formaciones }}^{\text {Pisos }}$ & & & & & & \\
\hline Especies & 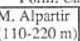 & $\begin{array}{l}\text { M. Sierra } \\
(10-150 \mathrm{~m})\end{array}$ & $\begin{array}{ll}\text { M.P. Tomo } \\
0.5-5 \mathrm{~m})\end{array}$ & $\begin{array}{l}\text { M. Huerva } \\
\text { (50.110 m) }\end{array}$ & M. Ccino & M. Recbosilita \\
\hline 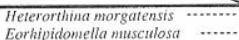 & $=$ & & & & & \\
\hline 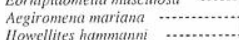 & $\cdots \cdots$ & & & & & \\
\hline Heterorthina kerfornei …......... & & & & & & \\
\hline 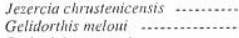 & ... & & $=$ & & & \\
\hline $\begin{array}{l}\text { Svoboddina armoricana } \\
\text { Resuschella herreraensis }\end{array}$ & $\cdots . .$. & & $=$ & - & & \\
\hline 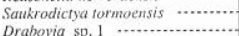 & & & & & & \\
\hline 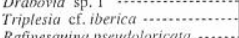 & (..... & & $=$ & & & \\
\hline 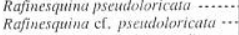 & ........ & & $=$ & & & \\
\hline 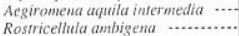 & & & & & & \\
\hline $\begin{array}{l}\text { Rostricellutat marcialiti : } \\
\text { Gelidorthis }\end{array}$ & & & - & & & \\
\hline $\begin{array}{l}\text { Hesperorthichae gen. et sp. indel. } \\
\text { Ond }\end{array}$ & & & & $=$ & & \\
\hline 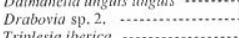 & $\cdots+\cdots$ & & & $=$ & & \\
\hline 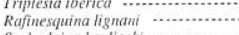 & ....... & & & $=-$ & & \\
\hline $\begin{array}{l}\text { Sviobodaina haviti } \\
\text { Drabovinella sp. }\end{array}$ & ........ $>$. & & & & & \\
\hline $\begin{array}{l}\text { Drabovia sp. } 3 \\
\text { Hisumba }\end{array}$ & & & & & & \\
\hline Dalmanella sp. & & & & & & \\
\hline $\begin{array}{l}\text { Triplessia cf, cymbutha } \\
\text { Leamgella anactya }\end{array}$ & & & & & & \\
\hline 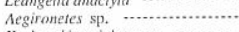 & & & & & & \\
\hline Kozilowskites ichuusae .............. & & & & & & \\
\hline 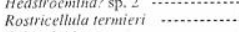 & & & & & & \\
\hline $\begin{array}{l}\text { Orbiculloidea sp. } \\
\text { s........... }\end{array}$ & & & & & $=$ & \\
\hline 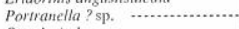 & & & & & & \\
\hline $\begin{array}{l}O_{1} \\
\end{array}$ & & & & & & \\
\hline Doferthis s. ..... & & & & & & $=$ \\
\hline Nicolelta acioniae spp. indet. ...... & & & & & & \\
\hline 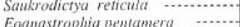 & & & & & & \\
\hline 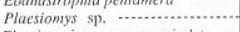 & & & & & & \\
\hline 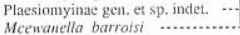 & & & & & - & \\
\hline $\begin{array}{l}\text { Mentaena sp. } \\
\text { Lep. }\end{array}$ & & & & & E & \\
\hline Skeniditoides cf. paucicostatus & & & & & & - \\
\hline 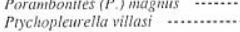 & & & & & & $=$ \\
\hline Schizophorella sp. . & & & & & & $=$ \\
\hline 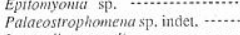 & & & & & & $=$ \\
\hline $\begin{array}{l}\text { Leptestipa pranti } \\
\text { Ledrsomina sp. } 1\end{array}$ & & & & & & $=$ \\
\hline
\end{tabular}

Figura 14. Distribución estratigráfica de los braquiópodos descritos en el Ordovícico medio y superior de la Cadena Ibérica Oriental (según Villas, 1985, 1992).

Respecto a los equinodermos, faltan estudios sistemáticos y bioestratigráficos detallados, a pesar de representar uno de los registros más continuos conocidos en Europa en torno al límite Cámbrico Inferior-Medio. Al final del Cámbrico Inferior, el geoevento Valdemiedes (Liñán, Fernández-Nieto et al., 1993) señala una de las primeras extinciones en masa de la historia geológica, que parece contemplar la extinción de varias familias de trilobites y la de la mayoría de grupos de arqueociatos (Debrenne, 1991). En muchas áreas, los nichos ecológicos dejados por los biohermos de arqueociatos se verán ocupados por praderas de equinodermos en el Cámbrico Medio, como se observa en el Norte de España.

El reciente descubrimiento de acritarcos en el Cámbrico Inferior y Medio de la localidad de Borobia presenta la novedad de que la zonación de acritarcos y los pisos regionales españoles establecidos con trilobites puedan ser comparados, potenciando la precisión de estos Pisos en las correlaciones globales entre provincias paleobiogeográficas.

Finalmente, la gran extensión estratigráfica que los materiales siliciclásticos tienen en la sucesión cambro-ordo- vícica sugiere la intensificación de los estudios paleoicnológicos como herramienta eficaz para complementar las interpretaciones paleoecológicas y sedimentológicas, cuando no bioestratigráficas.

En el Ordovícico quedan también una serie de grupos por estudiar, potencialmente muy interesantes por sus aplicaciones bioestratigráficas o paleoecológicas. Es el caso de los quitinozoos, que han demostrado una gran fiabilidad en la datación del Paleozoico en otros puntos de la región Mediterránea, y que podrían ayudar en el conocimiento cronoestratigráfico de nuestra región, con problemas en las correlaciones a larga distancia por la carencia de grupos planctónicos y el fuerte endemismo de las faunas bentónicas.

Los briozoos constituyen otro grupo muy interesante por su gran abundancia en las formaciones Fombuena y Calizas de Cistideos, pero todavía no han recibido un estudio adecuado. Aunque no muy frecuentes, gasterópodos, bivalvos y ostrácodos están presentes en el Caradoc y Ashgill, y su descripción está también por realizar. Lo mismo sucede con la mayoría de los trilobites y braquiópodos inarticulados del Tremadoc y Arenig incluidos en horizontes fosilíferos delgados que se encuentran dispersos en una serie terrígena muy potente.

\section{AGRADECIMIENTOS}

Este trabajo es una contribución a los Proyectos DGICYT PB93-0591, PB91-0671 y PB93-0410, y a los Proyectos del P.I.C.G n. 319 ("Global Palaogeography of Late Precambrian and Early Palaeozoic") y n 351 ("Early Paleozoic evolution in NW Gondwana").

\section{BIBLIOGRAFÍA}

Álvaro, J. 1995. Propuesta de una nueva unidad litoestratigráfica para el Cámbrico Medio-Superior de las Cadenas Ibéricas (NE de España): El Grupo Acón. Boletín de la Real Sociedad Española de Historia Natural (Sección Geológica), 90 (1-4), 95-106.

Álvaro, J., Gozalo, R. y Liñán, E. 1993. Bioestratigrafía del límite Cámbrico Inferior-Medio en Ateca (Cadena Ibérica Occidental, España). Revista Española de Paleontología, $\mathbf{n}^{\mathbf{0}}$ extr., 40-48.

Álvaro, J, Liñán, E, Gozalo, R. y Gámez Vintaned, J. A. 1993. Estratigrafía del tránsito Cordubiense-Ovetiense (Cámbrico Inferior) en la Cadena Ibérica Occidental (España). Cuadernos do Laboratorio Xeolóxico de Laxe, 18, 147-162.

Babin, C. and Gutiérrez-Marco, J. C. 1991. Middle Ordovician Bivalves from Spain and their phyletic and palaeogeographic significance. Palaeontology, 34, 1, 109-147.

Badillo, L. 1959. Catálogo de las especies fósiles del Museo del Instituto Geológico y Minero de España. Notas y Comunicaciones del Instituto Geológico y Minero de España, 55, 71-124.

Chauvel, J., Meléndez, B. et Le Menn, J. 1975. Les Echinodermes (Cystoïdes et Crinoïdes) de l'Ordovicien supérieur de Luesma (Sud de l'Aragón, Espagne). Estudios geológicos, 31, 351-364.

Chauvel, J. et Le Menn, J. (1979). Sur quelques Echinodermes (Cystoïdes et Crinoïdes) de l'Ashgill d'Aragón (Espagne). Geobios, 12 (4), 549-587. 
Carls, P. 1975. Zusätzliche Conodonten-Funde aus dem tiefen Unterdevon Keltiberiens (Spanien). Senckenbergiana lethaea, 56 (4/5), 399-428.

Debrenne, F. 1991. Extinction of the Archaeocyatha. Historical Biology, 5, 95-106.

Dereims, A. 1898. Recherches Géologiques dans le Sud de l'Aragon. Thèse Université de Lille, 1-199.

Donayre, F. M. 1873. Bosquejo de una descripción física y geológica de la provincia de Zaragoza. Memorias de la Comisión del Mapa Geológico de España, 1, 1-128.

Friedrich, W.-P. 1993. Systematik und Funktionsmorphologie mittelkambrischer Cincta (Carpoidea, Echinodermata). Beringeria, 7, 3-190.

Gámez-Vintaned, J. A. 1995. Los materiales prehercínicos de la Sierra del Moncayo (Cadena Ibérica Oriental, España) y su contenido paleoicnológico. Boletín de la Real Sociedad Española de Historia Natural (Sección Geológica), 90 (1-4), 21-50.

Gámez, J. A., Fernández-Nieto, C., Gozalo, R., Liñán, E., Mandado, J. y Palacios, T. 1991. Bioestratigrafía y evolución ambiental del Cámbrico de Borobia (Provincia de Soria, Cadena Ibérica Oriental). Cuadernos do Laboratorio Xeolóxico de Laxe, 16, 251-271.

Gámez Vintaned, J. A. y Mayoral Alfaro, E. 1992. Primeras aportaciones a la Paleoicnología del grupo Murero (Cámbrico inferior-medio) en Murero. (Provincia de Zaragoza. Cadena Ibérica Occidental). Geogaceta, 12, 100-102.

Gozalo, R., Alvaro, J., Liñán, E., Sdzuy, K. y Truyols, J. 1993. La distribución de Paradoxides (Acadoparadoxides) mureroensis Sdzuy, 1958 (Cámbrico Medio basal) y sus implicaciones paleobiogeográficas. Cuadernos do Laboratorio Xeolóxico de Laxe, 18, 217-230.

Gozalo, R. y Liñán, E. 1988. Los materiales hercínicos de la Cordillera Ibérica en el contexto del Macizo Ibérico. Estudios geológicos, 44, 399-404.

Gozalo, R., Liñán, E. y Alvaro, J. 1993. Bioestratigrafía del Cámbrico Medio de Villafeliche (Prov. Zaragoza, España). Revista Española de Paleontología, $\mathbf{n}^{\mathbf{0}}$ extr., 49-57.

Gutiérrez Marco, J. C. 1986. Graptolitos del Ordovícico español. Tesis Doctoral, Universidad Complutense, 1- 701. Inédita.

Gutiérrez Marco, J. C., Meléndez, B. y Chauvel, J. 1991. Equinodermos (Cistideos y Blastozoos) del Llandeilo y Caradoc (Ordovícico) de la Cordillera Ibérica. VII Jornadas de Paleontología, Oviedo, Resúmenes de comunicaciones, p. 37, Oviedo.

Hafenrichter, M. 1980. The lower and upper boundary of the Ordovician System of some selected regions (Celtiberia, Eastern Sierra Morena) in Spain. Part II: The Ordovician/Silurian boundary in Spain. Neues Jahrbuch für Geologie und Paläontologie, Abhandlungen, 160 (1), 138-148.

Hammann, W. 1983. Calymenacea (Trilobita) aus dem Ordovizium von Spanien; ihre Biostratigraphie, Ökologie und Systematik. Abhandlungen der senckenbergischen natursforschenden Gesellschaft, 542, 1-177.

Hammann, W, 1992. The Ordovician trilobites from the Iberian Chains in the province of Aragón, NE-Spain. I. The trilobites of the Cystoid Limestone (Ashgill Series). Beringeria, 6, 1-144.

Hammann, W., Robardet, M. and Romano, M. 1982. The Ordovician System in southwestern Europe (France, Spain, and Portugal). Correlation chart and explanatory notes. International Union of Geological Sciences Publication, 11, 1-47.
Havlíček, V. and Josopait, V. 1972. Articulate Brachiopods from the Iberian Chains, Northeast Spain (Middle Cambrian-Upper Cambrian-Tremadoc). Neues Jahrbuch für Geologie und Paläontologie, Abhandlungen, 140 (3), 328-353.

Havlíček, V and Kř́̌ž, I. 1978. Middle Cambrian Lamellodonta simplex, VOGEL: "Bivalve" turned Brachiopod Trematobolus simplex (Vogel). J. Paleont., 52 (5), 972-975.

Hernández Sampelayo, P. 1935. El Sistema Cambriano. Memorias del Instituto Geológico y Minero de España, 41, 291-528.

Hernández, A. y Olivé, A. 1983. Memoria explicativa de la hoja ${ }^{\circ}$ 566 (Cella) del Mapa Geológico de España esc. 1:50.000 (2. ${ }^{a}$ serie). I.G.M.E., Madrid, 68 pp.

Kolb, S. and Wolf, R. 1979. Distribution of Cruziana in the Lower Ordovician sequence of Celtiberia (NE Spain) with a revision of the Cruziana rugosa group. Neues Jahrbuch für Geologie und Paläontologie, Monatshefte, 8, 457-474.

Leone, F., Hammann, W., Laske, R., Serpagli, E. and Villas, E. 1991. Lithostratigraphic units and biostratigraphy of the post-sardic Ordovician sequence in south-west Sardinia. Bolletino della Società Paleontologica Italiana, 30 (2), 201-235.

Liñán, E., Fernández-Nieto, C., Gámez, J. A., Gozalo, R., Mayoral, E., Moreno-Eiris, E., Palacios, T. y Perejón, A. 1993. Problemática del límite Cámbrico Inferior-Medio en Murero (Cadenas Ibéricas, España). Revista Española de Paleontología, no extr., 26-39.

Liñán, E. and Gámez-Vintaned J. A. 1993. Lower Cambrian palaeogeography of the Iberian Peninsula and its relations with some neighbouring European areas. Bulletin de la Société géologique de France, 164 (6), 831-842.

Liñán, E. y Gozalo, R. 1986. Trilobites del Cámbrico inferior y medio de Murero (Cordillera Ibérica). Memorias del Museo Paleontológico de la Universidad de Zaragoza, 2, 1-104.

Liñán, E., Gozalo, R., Gámez, J. A. y Álvaro, J. J. 1992. Las formaciones del Grupo Mesones (Cámbrico Inferior-Medio) en las Cadenas Ibéricas. III Congreso Geológico de España y VIII Congreso Latinoamericano de Geología, Salamanca, Actas, 1, 517-523.

Liñán, E., Perejón, A. and Sdzuy, K. 1993. The Lower-Middle Cambrian stages and stratotypes from the Iberian Peninsula: a revision. Geol. Mag., 130 (6), 817-833.

Lotze, F. 1929. Stratigraphie und Tektonik des Keltiberischen Grundgebirges (Spanien). Abh. Ges. Wiss. Göttingen, math.-phys. Kl., n. F., 14 (2), 1-320. Traducción española por M. San Miguel de la Cámara (1954-55): Estratigrafía y tectónica de las Cadenas paleozoicas Celtibéricas. Publicaciones Extranjeras sobre la Geología de España, 8, 1-313.

Lotze, F. und Sdzuy, K. 1961. Das Kambrium Spaniens. Teil I: Stratigraphie. Akademie der Wissenschaften und der Literatur, Abhandlungen der mathematisch-naturwissenschaftlichen Klasse, 6, 1-216; Teil II: Trilobiten. Akademie der Wissenschaften und der Literatur, Abhandlungen der mathematisch-naturwissenschaftlichen Klasse, 7 (8), 217-408 (499-690).

Mallada, L. 1875. Sinopsis de las especies fósiles que se han encontrado en España. Boletín de la Comisión del Mapa Geológico de España, 2, 1-160.

Meléndez, B. 1944. Contribución al estudio del Paleozoico aragonés. Trabajos del Instituto de Ciencias Naturales José de Acosta, serie geol., 3 (1), 1-149.

Meléndez, B. 1959. Los Echinosphaerites del Silúrico de Luesma (Zaragoza). Estudios geológicos, 15, 23-28. 
Meléndez, B. y Hevia, I. 1947. La fauna ashgilliense del Silúrico aragonés. Boletín de la Universidad de Granada, 83, 1-17.

Mergl, M. and Liñán, E. 1986. Some Cambrian Brachiopoda of the Cordillera Ibérica and their biostratigraphical significance. In Villas, E. (coord). Memorias de las I Jornadas de Paleontología, Colección Actas, 5, Diputación General de Aragón, Departamento de Cultura y Educación, Zaragoza.159-180.

Nordford, B. S. 1988. Introduction to papers on the Cambrian-Ordovician Boundary. Geological Magazine, 125 (4), 323-326.

Owen, R. M. and Hammann, W. 1990. Proetide trilobites from the Cystoid Limestone (Ashgill) of NW Spain, and the suprageneric classification of related forms. Paläontologische Zeitschrift, 64 (3/4), 221-244.

Palacios, P. 1890. Reseña Geológica de la provincia de Soria. Memorias de la Comisión del Mapa Geológico de España, 16, 1-557.

Palacios, P. 1893. Reseña geológica de la región meridional de la provincia de Zaragoza. Boletín de la Comisión del Mapa Geológico de España, 19, 1-112.

Philippot, A. et Riba, O. 1952 a. Sur la faune graptolitique de la Sierra d'Albarracín (Chaine Ibérique). Comptes Rendus Sommaires de la Société géologique de France, 1952 (5), 74-75.

Philippot, A. y Riba, O. 1952 b. Nota sobre la fauna de graptolitos de la Sierra de Albarracín (Cordillera Ibérica). Estudios geológicos, 8 (16), 351-352.

Pillola, G. L., Gámez-Vintaned, J. A., Dabard, M. P., Leone, F., Liñán, E. and Chauvel, J.-J. 1994. The Lower Cambrian ichnospecies Astropolichnus hispanicus: palaeoenvironmental and palaeogeographic significance. Bolletino della Società Geologica Italiana, Spec. Vol. 2, 253-267.

Portero, J. M. 1983. Memoria explicativa de la hoja n. 565 (Tragacete) del Mapa Geológico de España esc. 1:50.000 (2." serie). I.G.M.E., Madrid, 89 pp.

Riba, O. 1959. Estudio Geológico de la Sierra de Albarracín. Monografías del Instituto Lucas Mallada, 16, 1-283.

Riba, O. 1982. Sierra de Albarracín. In XVI Curso de Geología Práctica. (Eds. M. Gutiérrez Elorza y J. L. Peña Monné). Teruel, 44-66.

Richter, R und Richter, E. 1948. Zur Frage des Unter-Kambriums in Nordost-Spanien. Senckenbergiana, 29 (1/6), 23-39.

Robardet, M. and Doré F. 1988. The late Ordovician diamictic formations from southwestern Europe: North Gondwana glaciomarine deposits. Palaeogeography, Palaeoclimatology, Palaeoecology, 66, 19-31.

Sacher, L. 1966. Stratigraphie und Tektonik der nordwestlichen Hesperischen ketten bei Molina de Aragón/Spanien. Teil I: Stratigraphie (Paläozoikum). Neues Jahrbuch für Geologie und Paläontologie, Abhandlungen, 124 (2), 151-167.

Schmitz, U. 1971. Stratigraphie und Sedimentologie im Kambrium und Tremadoc der Westlichen Iberischen Ketten nordlich Ateca (Zaragoza), NE Spanien. Münstersche Forschungen zur Geologie und Paläontologie, 22, 1-123.

Schroeder, R. 1973. Carpoideen aus dem Mittelkambrium Nordspaniens. Palaeontographica, Abt. A, 141, 119-142.

Sdzuy, K. 1958. Neue Trilobiten aus dem Mittelkambrium von Spanien. Senckenbergiana lethaea, 39, 235-253.

Sdzuy, K. 1961. Das K ambrium Spaniens. Teil II: Trilobiten. Akademie der Wissenschaften und der Literatur, Abhandlungen der mathematisch-naturwissenschaftlichen Klasse, 1961 (78), 217-408 (499-690).
Sdzuy, K. 1971a. Acerca de la correlación del Cámbrico inferior de la Península Ibérica. I Congreso Hispano-Luso-Americano de Geología Económica, Sección 1 Geología, 2, 753-768.

Sdzuy, K. 1971b. La subdivisión bioestratigráfica y la correlación del Cámbrico Medio de España. I Congreso Hispano-Luso-Americano de Geología Económica, Sección 1 Geología, 2, 769-782

Sdzuy, K. 1987. Trilobites de la base de la Formación Jalón. Revista Española de Paleontología, 2, 3-8.

Sdzuy, K. y Liñán, E. 1993. Rasgos paleogeográficos del Cámbrico Inferior y Medio del norte de España. Cuadernos do Laboratorio Xeolóxico de Laxe, 18, 189-215.

Seilacher, A. 1970. Cruziana stratigraphy of "non-fossiliferous" Palaeozoic sandstones. In: Trace fossils. (Eds. T. P. Crimes and J. C. Harper). Geological Journal Special Issue, 3 , 447-476.

Shergold, J. H. and Sdzuy, K. 1991. Late Cambrian trilobites from the Iberian Mountains, Zaragoza Province, Spain. Beringeria, 4, 193-235.

Torrubia, J. 1754. Aparato para la Historia Natural española. Imprenta de los herederos de Don Agustín de Gordejuela y Sierra, Madrid. t. 1, 204 pp. Facsímil del Instituto de Geología Económica, C.S.I.C-Universidad Complutense. Madrid 1974.

Valenzuela, J. I., Gámez, J. A, Liñán, E. y Sdzuy, K. 1990. Estratigrafía de la región de Brea. Cadena Ibérica Oriental. Boletín de la Real Sociedad Española de Historia Natural (Sección Geológica), 85, 45-54.

Verneuil, E. de. 1862. Descubrimiento de la fauna primordial en Zaragoza. Revista Minera, 13, 479.

Verneuil, E. de et Lartet, L. 1863. Sur la calcaire à Lychnus des environs de Segura (Aragón). Bulletin de la Société géologique de France (2ème série), 20, 684- 698.

Verneuil, E. de et Lorière, G. de. 1854. Aperçu d'un voyage géologique et tableau des altitudes prises en Espagne pendant l'été de 1853. Bulletin de la Société géologique de France, (2ème série), 11 (1853-1854), 661-712.

Villas, E. 1983. Las formaciones del Ordovícico medio y superior de las Cadenas Ibéricas y su fauna de braquiópodos. Estudios geológicos, 39, 359-377.

Villas, E. 1985. Braquiópodos del Ordovícico medio y superior de las Cadenas Ibéricas Orientales. Memorias del Museo Paleontológico de la Universidad de Zaragoza, 1, 1-153.

Villas, E. 1992. New Caradoc brachiopods from the Iberian Chains (Northeastern Spain) and their stratigraphic significance. Journal of Paleontology, 66 (5), 772-793.

Villas, E., Arbizu, M., Bernárdez, E., Méndez-Bedia, I. y Aramburu, C. 1995. Protambonites primigenius (Brachiopoda, Clitambonitidina) y el límite Cámbrico-Ordovícico en la Serie de los Cabos (Zona Asturoocidental-Leonesa, NO de España). Revista Española de Paleontología, 10 (2), 140-150.

Villas, E., Harper, D. A. T., Mélou, M. and Vizcaïno, D. 1995. Stratigraphical significance of the Svobodaina species (Brachiopoda, Heterorthidae) range in the upper Ordovician of South-Western Europe. In: Ordovivian Odyssey: Short Papers for the Seventh International Symposium on the Ordovician System. Las Vegas, Nevada, USA. June 1995. (Eds. J. D. Cooper, M. L. Droser and S. C. Finney). The Pacific Section of the Society for Sedimentary Geology (SEPM), Fullerton, 97-98.

Villena, J. 1976. Estudio geológico de un sector de la Cordillera Ibérica comprendido entre Molina de Aragón y Monreal (provin- 
cias de Guadalajara y Teruel). Boletín Geológico y Minero, 87 (4), 329-354.

Vogel, K. 1962. Muscheln mit Schlosszähnen aus dem spanischen Kambrium und ihre Bedeutung für die Evolution der Lamellibranchiaten. Akademie der Wissenschaften und der Literatur, Abhandlungen der mathematisch-naturwissenschaftlichen Klasse, 1962 (4), 193-244.
Wolf, R. 1980. The lower and upper boundary of the Ordovician System of some selected regions (Celtiberia, Eastern Sierra Morena) in Spain. Part I: The Lower Ordovician sequence of Celtiberia. Neues Jahrbuch für Geologie und Paläontologie, Abhandlungen, 160 (1), 118-137.

Manuscrito recibido: 13 de diciembre 1994 Manuscrito aceptado: 11 de Octubre 1995 